\title{
Ensino de gramática/análise linguística: uma professora, múltiplas práticas
}

\author{
Fabiana Júlia de Araújo Tenório \\ Instituto Federal de Educação, Ciência e Tecnologia de Pernambuco \\ Alexsandro da Silva \\ Universidade Federal de Pernambuco
}

\section{Resumo}

0 artigo analisa práticas de ensino de gramática/análise linguística desenvolvidas por uma professora do $6 .^{\circ}$ ano do ensino fundamental. Apoiandose em referenciais teóricos, relacionados ao ensino de gramática/análise linguística e aos saberes, e em práticas docentes, demonstrou-se, por meio de observações em aula e entrevistas, a existência de um movimento que oscila entre permanências e mudanças nas práticas de ensino observadas, o qual se materializou por meio dos seguintes aspectos: o uso do livro didático e a relação que a professora mantinha com esse recurso; a ênfase no trabalho com leitura e produção de textos; a articulação entre os eixos de ensino; e a abordagem dos conteúdos gramaticais.

Palavras-chave: Ensino de língua portuguesa. Análise linguística. Saberes docentes. Práticas de ensino. 


\section{Teaching grammar/ linguistic analysis: a teacher, multi- ple practices}

The article analyses practices of grammar teaching / linguistic analysis developed by a teacher of the 6th year of middle school. Drawing on theoretical frameworks related to the teaching of grammar / linguistic analysis and knowledge and teaching practices, it was demonstrated, through classroom observations and interviews, the existence of a movement between continuity and change in the teaching practices observed, which materialized through the following aspects: the use of textbooks and the relationship that the teacher had with this resource; the emphasis on working with reading and text production; the articulation between of axes teaching; and the approach of grammatical content.

Keywords: Teaching of portuguese language. Linguistic analysis. Teaching knowledge. Teaching practices.

\section{Enseñanza de la gramática / análisis lingüístico: una maestra, múltiples prácticas}

Este trabajo analiza prácticas de enseñanza de gramática / análisis lingüístico desarrolladas por una maestra de $6^{0}$ año de Educación Primaria. Basándose en referenciales teóricos relacionados a la enseñanza de gramática/ análisis lingüístico y a los saberes y las prácticas docentes. Se demostró, a través de la observación de clases y entrevistas, la existencia de un movimiento entre permanencia y cambios en las prácticas de enseñanza observadas, lo cual se hizo patente por medio de los siguientes aspectos: el uso del libro didáctico y la relación que la maestra mantenía con ese recurso; el énfasis en el trabajo con la lectura y la producción de textos; la articulación entre los ejes de enseñanza; y el abordaje de los contenidos gramaticales.

Palabras-clave: Enseñanza de la Lengua Portuguesa. Análisis lingüístico. Saberes docentes. Prácticas de enseñanza. 


\section{Introdução}

De um lado, eu acho que estou no caminho certo. Por outro, eu fico triste, porque o trabalho caminha mais lento, não é? Eles estão habituados a um ritmo e eu tô colocando outro. Então essa transição é para eles, como é para mim. Estamos num movimento, não é? (Professora participante da pesquisa)

Desde a segunda metade dos anos 80 do século $X X$, vem crescendo, no Brasil, o número de pesquisas relativas ao ensino de língua materna na educação básica. Esses estudos, conforme também pretendiam, acabaram por interferir em políticas de Estado, dando origem a documentos oficiais que defendiam mudanças no ensino de português, em um movimento circular de influências entre a comunidade disciplinar e as propostas oficiais. (cf. Busnardo; Lopes, 2010)

Nesse contexto, encontram-se as discussões sobre o ensino de gramática, que acompanharam as mudanças nas concepções de língua. Enquanto esta era concebida como uma estrutura, a gramática ocupava o mais alto nível de importância, e as aulas de português incidiam sobre estruturas gramaticais. Isso é questionado quando a língua passa a ser vista como uma forma de interação social, e o ensino de normas prescritivas e nomenclaturas deixa de ser, pelo menos nos âmbitos acadêmico e oficial, o foco das aulas daquela disciplina. Entretanto, como não poderia deixar de ser, distintas apropriações foram feitas: uns (umas) docentes passaram a usar o texto como pretexto para ensinar conteúdos tradicionais da gramática; outros (as), mais radicais, passaram a abolir todo e qualquer estudo relativo às estruturas da língua.

De acordo com Neves (2003), é obrigação da escola garantir que os alunos percebam a necessidade de adequar registros, para que possam transitar seguramente pelos diferentes padrões de uso da língua. Assim, a posição radical de "exterminar" a gramática das aulas de português é infundada, até porque, conforme assinala Antunes (2003), não existe língua sem gramática. Nessa perspectiva, torna-se necessário oportunizar aos alunos o contato com a norma linguística de prestígio social usada atualmente (Mattos e Silva, 2011) e possibilitar reflexões sobre quando e como utilizá-la.

Diante das diversas questões que emergem sobre o ensino de língua materna, elegemos, neste trabalho, a discussão sobre um dos eixos desse ensino: a análise linguística. Esse eixo didático - que assume o lugar do antigo "ensino de gramática" - ainda carece de investigações que auxiliem os professores em suas práticas de ensino, principalmente quando o comparamos 
aos eixos de leitura e produção de textos, cujas reflexões parecem ter sido mais amplamente difundidas e apropriadas entre os docentes. (Morais, 2002; Mendonça, 2006)

Neste artigo, objetivamos apresentar resultados de uma investigação sobre as práticas de ensino de gramática/análise linguística desenvolvidas por uma professora do $6 .^{\circ}$ ano do ensino fundamental de uma escola da rede pública de ensino, analisando, nessas práticas, aspectos que podem se relacionar a permanências e mudanças em relação à tradição do ensino gramatical. Considerando esse objetivo, apresentaremos, inicialmente, algumas reflexões teóricas sobre o ensino de gramática/análise linguística e sobre os saberes e as práticas dos professores no cotidiano da sala de aula. Em seguida, após situarmos os aspectos metodológicos da pesquisa, discutiremos os principais resultados do estudo e teceremos algumas considerações finais.

\section{Ensino de língua materna na escola: das aulas de gramática à prática de análise linguística}

Depois de um ensino voltado apenas para alfabetização, implantou-se, no Brasil Colônia, em 1759, na Era Pombalina, o ensino de língua portuguesa, que, de acordo com Soares (1998), seguia os moldes da tradição gramatical latina. De acordo com essa autora, esse modelo de disciplina servia às camadas sociais privilegiadas, já familiarizadas com o padrão linguístico valorizado, à época, pela escola. Nesse período, os manuais didáticos traziam textos de autores consagrados e muitas atividades gramaticais, para reforçar o "purismo linguístico". (Silva; Cyranka, 2009)

Só a partir das novas conjunturas políticas e sociais da década de 1960 , que impulsionaram a "democratização do ensino", é que aquele modelo de ensino começa a destoar da nova clientela da escola.

Para se adequar, então, a essa nova clientela, o ensino de língua portuguesa passou a ser orientado pela teoria da comunicação, recebendo um novo nome: "Comunicação e Expressão". Tanto Soares (1998) quanto Marinho (1998) concordam que foi a partir da instituição dessa nova disciplina que a linguagem oral apareceu nos livros didáticos e que houve uma ênfase nos tipos textuais e na utilização de textos dos domínios jornalísticos, publicitários, verbais e não verbais. Nesse contexto, “já não se trata mais de levar ao conhecimento do sistema linguístico - ao saber a respeito da língua - mas ao desenvolvimento das habilidades de expressão e compreensão de mensagens - ao uso da língua". (Soares, 1998, p. 57) 
Desse modo, o ensino de gramática perde sua importância, sendo relegado ao segundo plano. Essa perspectiva gera, assim, uma equivocada polêmica sobre a necessidade ou não de ensinar gramática na escola. Entretanto, conforme esclarece Marinho (1998, p. 48), "nem por decreto, como quis a lei 5.692/71, foi possível expulsar a gramática tradicional como conteúdo do ensino da língua pátria". Afinal, essa tradição ultrapassou séculos, impondose como condição supostamente necessária para aprender a falar e escrever corretamente.

A partir, principalmente, dos anos 80 do século $X X$, surge uma nova concepção de linguagem, que a entende como forma de interação social (Geraldi, 2003 [1984]). Como esclarece Soares (1998, p. 59), trata-se de "uma concepção que vê a língua como enunciação, discurso, [...] que, portanto, inclui as relações da língua com aqueles que a utilizam, com o contexto em que é utilizada, com as condições sociais e históricas de sua utilização". Nesse mesmo período, também se discute uma nova visão acerca do sujeito que aprende: ativo, interativo e inserido em um determinado contexto de práticas discursivas.

Nessa conjuntura, surge outra perspectiva de ensino de língua: a “prática de análise linguística". Inaugurando esse termo, Geraldi (2003 [1984]) propõe, defendendo a articulação entre os eixos do ensino de língua materna lleitura, produção e análise linguístical, que os professores partam da produção dos alunos para refletir sobre as questões estruturais e textuais da língua. Esse autor afirma, assim, que a “leitura de tais textos será a própria preparação das aulas de prática de análise linguística”. (Geraldi, 2003 [1984], p. 68)

Ao longo dos anos, o conceito de "prática de análise linguística" foi, porém, rediscutido. Nesse sentido, outras reflexões apontaram a necessidade de repensar alguns aspectos da proposta inicial de Geraldi, entre eles, a necessidade de, por vezes, abordar aspectos que não dependem apenas das produções dos alunos, mas podem englobar, por exemplo, o uso de diferentes recursos linguísticos nos textos de escritores experientes. (Morais, 2002; Mendonça, 2006)

Desse modo, o conceito de análise linguística contempla, conforme Mendonça (2007, p. 95), a construção de sentido nos usos linguísticos diversos e não toma apenas a produção dos alunos como ponto de partida para esse "movimento de reflexão sobre o funcionamento da linguagem". Além dessas produções, os textos e gêneros que circulam socialmente, nos mais diversos domínios discursivos, seriam objeto de reflexão.

Para, então, compreender o que é análise linguística - considerando a necessidade da reflexão consciente sobre a linguagem que se usa -, urge 
esclarecer que essa prática contempla, conforme Morais (2002) e Morais e Silva (2007), duas dimensões: a textualidade (conhecimentos relativos ao uso de recursos linguísticos que permitem compreender e produzir diversos textos) e a normatividade (conhecimentos relativos à correta notação escrita e ao domínio da norma linguística de prestígio sociall.

Essas dimensões textuais e normativas podem e precisam ser abordadas, quando pertinentes, de modo articulado aos eixos de leitura e produção de textos. Entretanto, os aspectos normativos também podem ser explorados em um trabalho a posteriori, ou mesmo à parte. Assim, a análise linguística poderá vir articulada à leitura, à produção, mas, também, poderá ser desenvolvida, em alguns casos, em situações não relacionadas a um texto ou gênero.

A prática de análise linguística não é, assim, nem um novo método, nem uma nova roupagem para ensino de gramática, não se resumindo, portanto, a um novo jeito ou a uma nova estratégia para apenas transmitir regras prescritivas, conceitos e definições. Não se trata também de usar o texto como pretexto para repetir as práticas pouco reflexivas que ocorriam (ou ocorrem) na escola.

Trata-se, ao contrário, de refletir sobre a língua portuguesa, sem se limitar ao ensino de classificações e nomenclaturas e de regras prescritivas que não se relacionam com os atuais usos linguísticos. É uma atividade que possibilita compreender os fenômenos linguísticos na dimensão da textualidade e da normatividade, o que poderá contribuir para a formação de leitores e produtores de textos.

Na tentativa de melhor compreender as práticas de ensino de gramática/ análise linguística, desenvolvidas no cotidiano da sala de aula, e as mudanças e permanências nessas práticas em relação à tradição do ensino gramatical, apoiar-nos-emos, também, em discussões sobre os saberes e as práticas docentes, o que constitui objeto de discussão da próxima seção.

\section{Saberes e práticas docentes no cotidiano da sala de aula}

Para discutir o ensino de gramática/análise linguística, faz-se necessário compreender o percurso histórico do qual tratamos anteriormente, além de considerar que esse percurso está atrelado aos saberes que os professores mobilizam em sala de aula, os quais podem ser determinantes na compreensão das práticas de ensino. Para Tardif (2000), não é possível estudar uma situação de ensino sem levar em conta os saberes do professor mobilizados em sua atividade docente. 
Assim, um primeiro aspecto a considerar é que há uma conjuntura cíclica que se instala na história do docente, no ambiente da escola: o aluno que se tornou professor e carrega consigo marcas e experiências anteriores à sua decisão de formar-se como professor.

Para Tardif \& Raymond (2000), o professor, durante toda sua trajetória pessoal e como aluno, apreende uma série de conhecimentos, valores e técnicas que são interiorizados e, posteriormente, utilizados como referência para as situações de atuação docente em sala de aula. Tratam-se, segundo esses autores, de "saberes pré-profissionais".

Podem-se elencar, além desses, segundo Tardif (2000), outros saberes docentes: os "saberes da formação profissional", que são difundidos pelas instituições de formação de professores; os "saberes disciplinares", que correspondem aos diferentes campos de conhecimento, os quais se encontram organizados sob a forma de disciplinas pelas instituições de formação inicial e continuada; os "saberes curriculares", que se apresentam sob a forma de programas escolares e integram objetivos, conteúdos e métodos; e os "saberes experienciais", que surgem no desenvolvimento da ação docente, no trabalho cotidiano da escola e na sala de aula. Portanto, a prática do professor "integra diferentes saberes, com os quais o corpo docente mantém diferentes relações". (Tardif, 2000, p. 36)

Além de compreender que o professor mobiliza variados saberes na sala de aula, é importante ressaltar, como afirma Chartier (2000), que a atividade docente possui um tempo relativamente longo, o que permite a utilização de práticas múltiplas que mais se coadunem aos fazeres cotidianos. A autora supracitada afirma, ainda, que os professores têm necessidade dos saberes científicos, mas apenas como ferramentas e não como dogmas. Assim, para a Chartier (2010), somente a aquisição de saberes científicos ou apenas a reflexão sobre a prática não é suficiente para provocar mudanças nas ações docentes.

No cotidiano da sala de aula, os professores, por vezes, subvertem a ordem das "estratégias" impostas e, por meio de "táticas" (Certeau, 1994), ajustam as políticas propostas para o ensino. Essas táticas se apresentam como uma possibilidade de reorganizar as práticas de ensino a partir das necessidades cotidianas.

Na área de língua portuguesa, os professores mobilizarão, em sala de aula, provavelmente, elementos de sua formação como alunos - a qual pode ter consistido, principalmente, no contato com um ensino de língua baseado quase exclusivamente em classificações e nomenclaturas gramaticais e regras prescritivas -, assim como também saberes que foram adquiridos na 
formação profissional, mas que antes foram validados pela experiência no cotidiano da sala de aula.

Assim, as práticas dos professores não podem ser analisadas sem considerar que estes, ao recebem e interpretarem as políticas educacionais, as orientações curriculares, isto é, as estratégias pensadas no exterior e no interior da escola, o fazem de acordo com sua maneira particular de agir, que não corresponde necessariamente às prescrições instituídas.

Considerando tais discussões, assumimos, portanto, a perspectiva de que os saberes e as práticas dos professores não correspondem às prescrições, sejam elas oriundas do campo teórico, sejam de outros campos institucionais, mas decorrem de um complexo processo no qual se entrelaçam experiências pré-profisssionais, conhecimentos da formação profissional e experiências vivenciadas durante o exercício da ação docente, especialmente no contexto da sala de aula.

\section{Percurso metodológico}

Tendo como foco as práticas dos professores no ensino de gramática/ análise linguística, a pesquisa que desenvolvemos foi realizada na intenção de compreendê-las, considerando a possibilidade de encontrar não apenas um, mas diversos sentidos para o fazer cotidiano na sala de aula. Essa opção teórico-metodológica visou, principalmente, compreender os aspectos das práticas dos professores como eles realmente se apresentam e não como um objeto a ser comparado com modelos idealizados teoricamente.

Isso posto, é possível justificar a escolha por uma abordagem qualitativa, que permitiu ir além da observação controlada e da suposta objetividade analítica. Essa opção pareceu contemplar a complexidade do nosso objeto de estudo e, ancorados em Lüdke (2006), podemos afirmar que trouxe maior abertura e liberdade para escolher os meios mais pertinentes para sua compreensão.

Assim, os procedimentos de produção dos dados que auxiliaram no olhar mais amplo para a complexidade do objeto foram as observações e as entrevistas. A observação, segundo Lüdke \& André (1986, p. 26), ocupa um lugar privilegiado nas pesquisas educacionais com abordagem qualitativa, uma vez que ela permite adentrar na perspectiva dos sujeitos e compreender, por meio do contato direto e pessoal do pesquisador, o fenômeno que se quer estudar. E, para colaborar no entendimento do que foi observado, fez-se uso de entrevistas semiestruturadas. A opção por esse tipo de entrevista está 
na condição, segundo Rosa \& Arnoldi (2008), de permitir a verbalização e a livre explicação sobre o que os sujeitos pensam, quais valores e tendências perpassam por eles. Isso foi feito, seguindo ainda as orientações dessas autoras, à luz do referencial teórico, lente que auxiliou a enxergar a realidade e elaborar as perguntas que melhor direcionassem a pesquisa para o foco desejado.

A pesquisa que desenvolvemos foi realizada com uma professora que possuía 38 anos de idade e 18 anos de experiência na rede pública de ensino, além de formação em letras, concluída em 2000, e especialização em linguística, concluída em 2001. Atuava em uma escola da rede municipal de ensino de Pesqueira - PE, local onde ocorreu a pesquisa, e ministrava aulas de língua portuguesa em turmas dos anos finais do ensino fundamental.

As observações em sala de aula (totalizando quinze aulas, cada uma com 45 minutosl foram realizadas em uma turma do $6 .^{\circ}$ ano do ensino fundamental e tiveram como objetivo analisar os aspectos nas práticas de ensino da professora que revelavam permanências e mudanças no ensino de gramática/análise linguística. Para isso, utilizamos a gravação de áudio para complementar as anotações registradas e permitir maior fidelidade aos dados gerados.

As entrevistas ocorreram em dois momentos distintos. Primeiramente, em algumas observações, realizamos pequenas entrevistas sobre os objetivos da aula, as dificuldades encontradas para atingir esses objetivos e ainda sobre alguns outros aspectos pertinentes para compreendermos melhor 0 contexto das observações. Em seguida, ao término de todas as observações, foi realizada uma entrevista final, retomando algumas questões sobre a formação e as práticas de ensino da professora.

Utilizou-se como método de análise de dados a análise de conteúdo (Bardin, 1977). De maneira indutiva, as categorias emergiram das falas da professora, das atividades e dos aspectos das suas práticas de ensino. Os dados, conforme será apresentado a seguir, não foram analisados isoladamente, uma vez que as pequenas entrevistas e a entrevista final subsidiaram a compreensão das práticas observadas em sala de aula.

\section{Práticas de ensino de gramática/análise linguística: entre mudanças e permanências}

0 interesse desse trabalho reside na compreensão das práticas de ensino como elas são e não na análise destas tendo em vista uma idealização 
teórica. Não se está em busca do certo ou errado, do professor que adequou suas práticas às teorias e discussões acadêmicas, ou do professor que ainda resistiria à mudança: compreender as práticas é enxergá-las como são, deixar emergir as suas possíveis causas e razões, escutar como o docente pensa, planeja e desenvolve suas aulas, perceber como ele se relaciona com essa prática e, após ter acesso a todos esses aspectos, organizar as informações, de maneira metodológica e responsável, relacionando-as e interpretando-as, a fim de possibilitar uma discussão sobre o que os professores fazem e não sobre o que deveriam fazer.

Assim, dentre as práticas observadas nas aulas da professora, destacaremos quatro aspectos que possibilitaram compreender o seu fazer nas aulas de língua portuguesa e o movimento entre permanências e mudanças no ensino de gramática/análise linguística. 0 recorte dos aspectos que foram relevantes nas práticas de ensino da professora está organizado da seguinte forma: o uso do livro didático e a relação que a docente mantinha com esse recurso; a ênfase no trabalho com textos; a articulação entre os eixos de ensino; e a forma como abordava os conteúdos gramaticais. São esses aspectos que abordaremos a seguir.

\section{0 uso do livro didático em sala de aula: uma dupla relação}

0 primeiro aspecto que discutiremos será a relação da professora com o livro didático e o uso desse material. A docente afirmou usar o livro adotado pela rede de ensino em que atuava por uma obrigatoriedade da escola, mas não reconhecia nele uma proposta adequada às suas práticas e à sua compreensão sobre o ensino de língua. Desse modo, fazia uso do livro adotado nas aulas de leitura e, às vezes, de produção de textos, mas utilizava outro livro para abordar os conteúdos gramaticais.

O livro adotado pela rede apresentava, conforme resenha do guia do Programa Nacional do Livro Didático (PNLD), uma abordagem transmissiva dos conteúdos gramaticais (Brasil, 2010), e a professora parecia, conforme veremos adiante, buscar o "diferente", que estaria na reflexão sobre os recursos da língua e sobre os sentidos provocados no texto pelo uso de tais recursos. Segundo o guia do PNLD, o livro usado pela rede traz a "seção Sistematizando (que) apresenta definições e classificações de categorias gramaticais e atividades que buscam a fixação dessas categorias em frases soltas, numa perspectiva tipicamente estrutural" (Brasil, 2010, p. 86). Um exemplo que ratifica a análise do guia está no seguinte enunciado de uma 
atividade proposta por esse livro: “Leia: Nasci de uma saia vermelha de Tia Anastácia. Identifique nesse trecho um substantivo, um adjetivo e uma locução adjetiva." (Sett, 2009, p.20)

Quando interpelada a falar sobre a diferença entre o livro adotado pela rede em que atuava e o outro livro de onde ela retirava as atividades gramaticais, ela explicou:

Totalmente [diferente]. Porque no meu livro [o livro adotado na escola] é mais, assim, em cima de textos longos. Tem um lado bom, assim... tem poemas, coloca os alunos para pensar... [mas] a gramática é trabalhada totalmente isolada. Os outros [os outros livros que ela usa para as atividades em sala de aula e para as provas] têm os textos, têm a gramática contextualizada, os exercícios também são com textos... e tem uma coisa... eles fazem uma introdução... [...] com um texto com o assunto que será abordado mais à frente. Que é o que nós utilizamos hoje [na aula]. Aí, lá na frente, vem conceituando. (06/08/12)

Esse primeiro aspecto das práticas de ensino da professora parece revelar uma maneira "particular" de atuar, modificando, como afirma Certeau (1994), o que é imposto pela instituição, subvertendo um ritual programado para o cotidiano da sala de aula. Não utilizar o livro didático adotado pela escola para ensinar gramática era adequar as imposições às necessidades cotidianas, uma vez que, nesse caso específico, havia a obrigatoriedade de utilizar o livro didático adotado pela rede. Assim, a professora subvertia sutilmente essa imposição na tentativa de adequar o seu fazer às demandas surgidas em sua prática cotidiana.

Essa tática apontava uma preocupação da professora em buscar atividades que se aproximassem do que ela considerava importante para os alunos. No entanto, afirmou ser o livro da escola que determinava a seleção e a ordem dos conteúdos a serem estudados no ano letivo, conforme podemos observar no seguinte extrato de entrevista:

Entrevistadora - Como você organiza suas aulas?

Professora - Eu faço assim, eu vou seguindo o livro, não é? Por exemplo, cheguei em produção textual naquela aula, mas eu achei que ficou dúvida... então eu continuo em produção textual. Aí terminei, eu vou para parte de gramática, então eu vou pra outros livros, tiro xerox e começo a trabalhar...

Entrevistadora - A definição [dos conteúdos] é feita pelo livro?

Professora - É. Pelo livro, mas não me impede de articular outras coisas para conseguir aquele objetivo. Mas veja: às vezes eu tô dando uma coisa aqui na página 100, mas uma coisa lá na página 130 tem uma ligação com o que eu estou 
dando... então eu pulo lá pra página 130. Porque vai me ajudar... 0 livro é pra ser seguido, mas não diz que é página por página.

Aqui, a professora deixa claro que quem ditava a ordem dos conteúdos gramaticais ensinados era o livro adotado pela rede. Entretanto, ela analisava o livro e, se fosse preciso, fazia algumas alterações que melhor organizassem a sequência que ela considerava adequada para seu trabalho. Além disso, conforme dissemos anteriormente, a docente recorria a explicações e atividades de outros livros didáticos, ainda que seguisse a sequência definida por esse material.

A relação que a professora estabelecia com o livro didático orientavase, portanto, por duas perspectivas. A primeira era de "fidelidade", quando seguia a ordem dos textos para leitura e dos conteúdos de gramática ensinados. A outra era de "rejeição" ao modelo apresentado nas atividades de gramática, quando recorria a outras formas de promover a aprendizagem que mais se adequassem ao modo como concebia o ensino e a aprendizagem de conhecimentos linguísticos.

Assim, se por um lado o livro institucionalizado apontava estratégias para promover a aprendizagem dos conteúdos gramaticais, a professora fazia uso de táticas que driblavam o que não era útil à sua realidade, confirmando a negação de sua posição de passividade enquanto consumidor (Certeau, 1994) dos produtos "fabricados" para auxiliar a prática de ensino.

\section{As práticas de leitura e produção de textos como foco das aulas de língua portuguesa}

Um segundo aspecto que destacaremos nas práticas de ensino da professora foi a ênfase que ela deu ao trabalho com textos. No período das observações, a maior parte do tempo foi dedicada à leitura e produção de textos, pois, das 15 (quinze) aulas observadas, 8 (oito) delas envolviam leitura e interpretação de textos, 5 (cinco) contemplavam produção e apenas 3 (três) foram dedicadas à análise linguística.

Quando interpelada a falar sobre suas aulas de leitura e produção, a professora demonstrou a importância que os textos tinham em suas aulas, e isso corrobora com a ideia de que os docentes parecem ter claramente a preocupação de formar alunos que leem, compreendem e escrevem textos, como também constatou Morais (2002). Eis o que disse a docente sobre o trabalho que desenvolvia com os textos: 
Nas aulas de leitura, eu uso o livro didático, tem a interpretação oral e a escrita dentro do livro e... na parte de gramática eu gosto de botar aqueles textos pequenos, mas sempre fazendo a interpretação de tirinhas... pra, aí sim, trabalhar a gramática, e tem também as produções textuais que eu faço a partir de uma gravura que tem que ter a leitura e a compreensão, a interpretação também com tirinhas...

Para produção não [uso o livro]. Leitura e interpretação [apenas para isso ela usa o livro]. A parte de gramática, como é muito resumida, eu trabalho em outros livros... Uma coisa que eu descobri: por exemplo, eu boto pra casa uma leitura e as interpretações orais e escritas... então vai pra casa, sem eu explicar nada... quando chega na sala [de aula] eles já têm um certo conhecimento do texto, já têm feito as interpretações. Aí eu vou ler com eles... Não é uma coisa totalmente desconhecida, porque eles já leram em casa. Então, já é melhor a discussão do texto.

Por outro lado, foi possível também perceber que a obrigatoriedade do uso do livro adotado pela rede de ensino na qual atuava parece ter sido um fator influente nessa decisão de trabalhar bastante a leitura. 0 livro possuía muitos textos e a professora organizava seu tempo em sala de aula para realizar a leitura e as atividades de compreensão - oral e escrita - propostas, a fim de também cumprir a exigência de usar o livro.

Outra informação interessante para análise desse segundo aspecto é que a professora recordou, em uma das entrevistas, de uma experiência vivida quando era aluna dos anos iniciais do ensino fundamental là época "ensino primário") que parece ter influenciado sua prática como docente. Ao responder sobre o que se lembrava das aulas e da professora de português na educação básica, ela respondeu:

[Lembro] Principalmente o relógio com dicas de produção... onde ele parasse, aí a professora, dos temas, nos dava orientação, explicação e, aí sim, pra gente escrever.

Não, lembro não [da professora de português nesse período]. Assim, do programa alfa ${ }^{1}$ não. No ensino médio, eu lembro. Era aquela que sentava no birô, conjugava todos os verbos e, aí, se errasse... E produção... interessante: no fundamental I eu vi muito de produção. Quando passou para o ll teve uma queda imensa. Eram só

1. Esse programa, mencionado pela professora na entrevista, foi desenvolvido em diversos Estados do Brasil na década de 1970, com o propósito de minimizar o fracasso escolar e diminuir o número de reprovações na $1^{a}$ série do $1^{\circ}$ grau. (cf. Bernardes, 2002) 
aulas de gramática.

Eu sempre foco que o programa alfa me ajudou muito no fundamental II. Porque supriu muito... Imagine se eu não tivesse tido... em relação à escrita e produção de textos. (Entrevista final)

Ainda sobre esse programa, a professora reiterou, muitas vezes, nas rápidas conversas entre as aulas, a importância dele para sua formação como leitora e escritora de textos. Esse depoimento parece confirmar, assim, o que dizem Tardif \& Raymond (2000) sobre as fontes pré-profissionais que contribuem para a formação do educador.

Provavelmente, no início da década de 1980 - período em que a professora cursou o ensino fundamental -, o trabalho com os gêneros, contemplando finalidades sociais de escrita e interlocutores diversificados, ainda não tinha se difundido, e isso também parece ser reeditado em sua prática: havia uma preocupação em formar leitores e produtores de textos, embora sem 0 trabalho focado nos gêneros e nos seus usos sociais.

0 programa anteriormente mencionado, assim como outros fatores relacionados aos saberes mobilizados pela professora, parece ter exercido uma influência nas suas práticas de ensino, considerando que o conjunto dos saberes adquiridos e modificados ao longo do tempo de discência é essencial para as escolhas que o professor realiza em sala de aula.

Diante dessa ênfase no trabalho com textos, é possível perceber um movimento constituído de práticas plurais, as quais se organizam por meio de atividades sustentadas por concepções aparentemente contraditórias, mas que encontram sua coerência diante dos objetivos da professora. Chartier (2000) ajuda a pensar sobre esse aspecto quando trata da coerência pragmática - o professor organiza suas práticas para atender aos seus objetivos, não as descartando ou as escolhendo a partir de concepções teóricas.

\section{A articulação entre leitura, produção de textos, análise linguística}

Outro aspecto presente nas práticas de ensino da professora referiu-se à articulação entre os eixos de ensino da área de língua portuguesa. Neste artigo, abordaremos um recorte dessa prática vinculado à reescrita dos textos, que se mostrou como um caminho para materializar a articulação da produção de textos com a análise linguística. Para essa articulação, a professora realizava acompanhamento individual e coletivo, visando intervir 
nas produções e instigar a reflexão dos alunos sobre o processo de escrita e as adequações pertinentes a ele.

Um exemplo disso foi uma atividade de produção de texto que propôs a partir de uma tirinha:

Figura 1: Atividade de produção de texto proposta pela professora

\section{Produçăo de texto}

Habilidade: Produzir pequeno texto a partir de gravura.

Leia os quadrinhos com atenção:

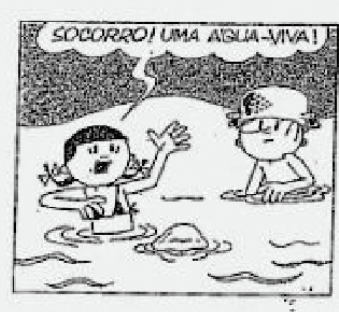

Conte como tudo aconteceu!

Dê um título à história e a continue:

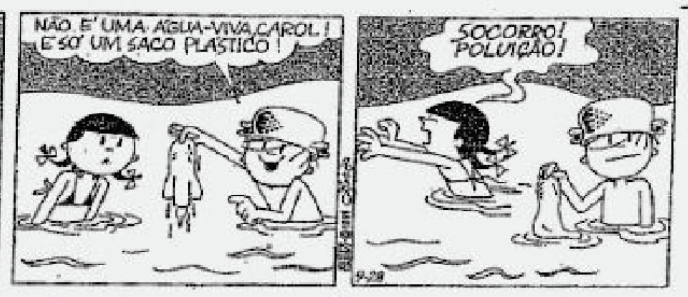

Ziraldo, Omenino mahquinho (As meihores tiras), L\&PM Editores

Certo dia o Menino Maluquinho e

Fonte: Elaborado pela professora 
Desde o início dessa atividade, a professora pontuou, em sua fala, algumas observações sobre aspectos relativos aos usos linguísticos (letras maiúsculas, pontuação, sentido), para que os alunos, ao escreverem a primeira versão do texto, estivessem atentos aos sentidos promovidos pelo uso da língua, mas também às questões gramaticais.

Durante a observação da aula, percebeu-se uma exploração dessas questões todas as vezes que os alunos se dirigiam à mesa da professora, para perguntar se estavam indo bem. Ela, prontamente, explicava a paragrafação, as letras maiúsculas e observava a concordância entre os sujeitos e os verbos.

Percebeu-se, ainda, outro momento de articulação que se efetivou logo após o término da produção feita por eles: depois que todos terminaram, a professora propôs um breve ensaio de reescritura, pedindo que os alunos fizessem uma nova leitura, observassem a escrita e verificassem se havia necessidade de alteração.

Nessa situação, embora a revisão tenha tido apenas um objetivo didático aprender a revisar -, a docente articulou a produção aos aspectos gramaticais (uso de parágrafos, concordância e de letras maiúsculas) e abordou a estrutura narrativa (sequência dos fatos e os elementos necessários para narrar). Assim, mesmo não explicitando o gênero, as suas características e condições de produção, ela explicou a tipologia e os elementos básicos da narração. Em um dos momentos, um aluno levou o texto para a professora ler:

Professora - Agora capriche... e cuidado, viu? Você tá repetindo muito "Carol, Carol, Carol"... Lembre que a gente pode substituir por um pronome... "ela".

Aluno - Se botar a menina aqui... pode ser?

Professora - Pode.

Professora (dirigindo-se para a turma) - Vejam bem. 0 próprio quadrinho da tirinha já ajuda. Porque já diz o que está acontecendo, onde aconteceu, quem eram as pessoas.... Tudo está no primeiro quadrinho. No segundo quadrinho a gente vai dizer, vai desenrolar a história, o que foi que aconteceu... o que foi que os personagens fizeram... e no terceiro quadrinho, no fim... o final da história, o que foi que aconteceu, como terminou. Então aqui é como se fosse a representação, Emanuel [o aluno que perguntou], do início da história, do meio, o desenvolvimento e do final.

$\mathrm{Na}$ aula seguinte, a professora entregou os textos contendo as anotações e observações escritas por ela durante a correção e pediu que reescrevessem o texto a partir delas. Além disso, percebeu-se que analisou os textos dos alunos e selecionou algo que eles erraram com maior frequência para refletir coletivamente com eles. 
Agora dê uma paradinha e olhe para a professora. Veja bem, todas as vezes que nós vamos reescrever o texto, nós temos que observar o que foi que nós erramos. Porque, se eu estou narrando um fato passado, um fato que aconteceu, o texto tem que ficar todo no pretérito, todo no passa-do [diz a palavra segmentando a última sílaba]. Aí alguns alunos se confundiram... colocaram como se a história ainda fosse acontecer, mais na frente como se já tivesse acontecido... aí fica desencontrando a ideia. A gente tem que ver a estrutura do texto... Teve gente que esqueceu o título da produção textual?! Se eu [es]tiver começando um parágrafo? Aí eu tenho que começar com letra maiúscula... Teve pessoas... por exemplo: o Menino Maluquinho e Carol... Carol se assustou, Carol botou para gritar, Carol saiu correndo... Então a repetição de palavras... repetição das mesmas palavras... onde nós já estudamos que o pronome pode substituir, não foi assim? Então, muitas vezes é a pressa de terminar o texto.

Essa fala da professora foi acompanhada de pequenas anotações no quadro com as palavras-chave do que ela estava explicando. Visivelmente, a professora explorava os aspectos normativos, como os tempos verbais, e textuais, como o uso de pronome como elemento de coesão. Essas explicações não vieram isoladas, mas a partir de uma situação de produção de texto. A prática de análise linguística não exclui o uso das regras (Antunes, 2007), e a professora utilizava a análise da língua contemplando diversas competências, fossem elas de notação escrita, de apropriação da norma linguística de prestígio, fossem ligadas à composição textual. (Morais, 2002)

Diante desse modo particular de fazer, a professora pareceu demonstrar consciência da necessidade de trabalhar os conteúdos gramaticais numa perspectiva diferenciada da que comumente vivenciara enquanto aluna e no período inicial de sua profissão. Isso aponta um movimento presente no cotidiano da sala de aula, à medida que a professora rejeitava o papel de passividade e assumia o de protagonista de suas práticas.

\section{A abordagem dos conteúdos gramaticais em sala de aula: entre o ensino de classificações e a reflexão sobre a língua}

0 último aspecto analisado nas aulas da professora, que se referiu ao modo como ela abordava os conteúdos gramaticais, reforça a nossa interpretação de que a docente encontrava-se em um movimento no qual ora se evidenciavam mudanças, ora permanências. Nesse último caso, principalmente, quando favorecia o trabalho da professora ou possibilitava maior segurança em suas práticas de ensino. 
A professora iniciava a abordagem dos conteúdos gramaticais com classificações, relembrava conceitos já vistos e parecia muito confortável nessa abordagem mais tradicional. Entretanto, esse não foi o foco de sua prática de ensino. Logo em seguida, promovia a reflexão, instigava os alunos a pensarem sobre as possibilidades de uso da língua e utilizava o erro como objeto de aprendizagem. Isso demonstrou, explicitamente, o uso de múltiplas práticas que atendiam à coerência pragmática de seu trabalho. (Chartier, 2000)

Para ilustrar essa abordagem, analisemos uma de suas aulas, a qual teve como conteúdo o gênero dos substantivos. No início, a professora relembrou o conteúdo, delimitando, no quadro, o que era gênero, número e grau. À medida que escrevia, também explicava, nomeando as flexões de gênero, explicando que eram masculino e feminino, e de número, que eram singular e plural.

Esse momento inicial de aula remetia às práticas tradicionais que seguem a sequência definição, exemplos e exercícios. A professora pareceu, no entanto, sentir-se à vontade para introduzir o assunto com as classificações. E, nesse sentido, é preciso pontuar que, quando explicava, sempre perguntando aos alunos, recebia respostas imediatas da turma. Isso demonstra que os alunos já conheciam essas classificações, que provavelmente foram estudadas em anos anteriores.

Em seguida, a docente mudou a abordagem de classificação para reflexão sobre a língua. A seguir, apresentamos um recorte da atividade utilizada, a qual havia sido retirada de outro livro didático, segundo sua explicação:

Figura 2: Atividade de gramática proposta pela professora

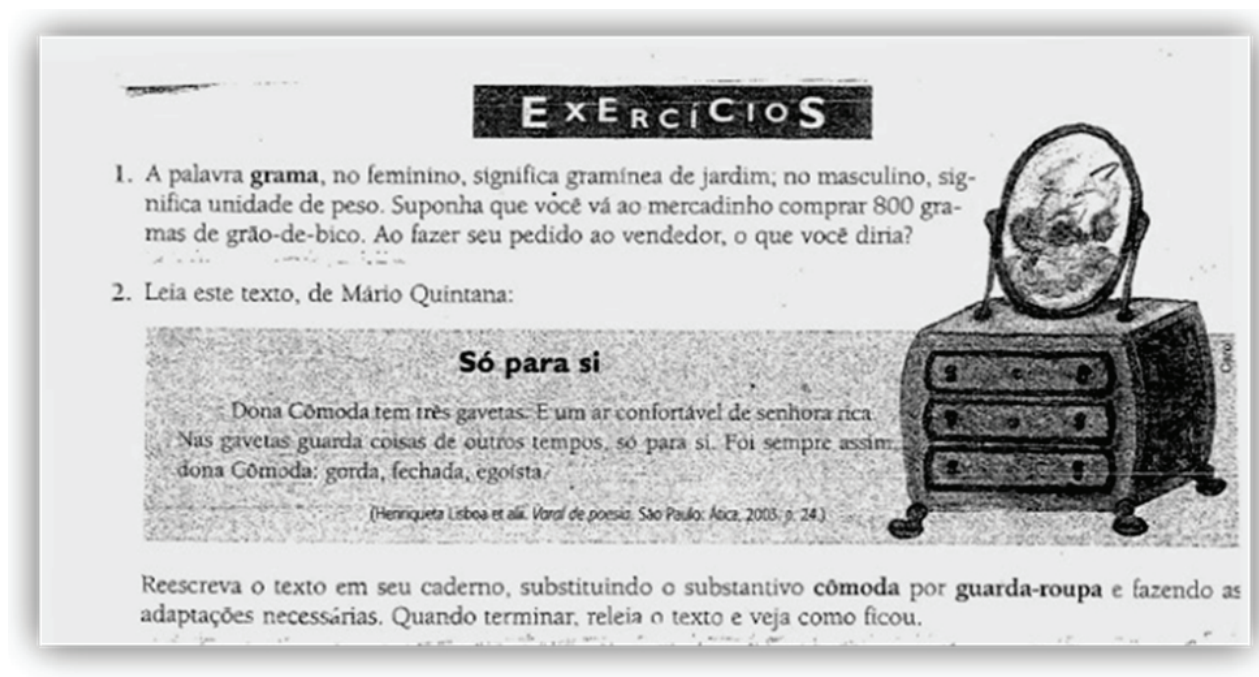

Fonte: Cereja, 2009, p. 115. 
A atividade proposta sobre gênero e número de substantivos e adjetivos (Fig. 2) solicitava que os alunos reescrevessem o poema de Mário Quintana, substituindo a palavra feminina (cômoda) por uma masculina (guarda-roupa). Os alunos ditaram o texto já realizando as modificações, a professora escreveu no quadro e pediu que eles lessem em voz alta. De início, não fazia observações, apenas escrevia o que os alunos ditavam. Depois, fez a leitura com os alunos e instigou-os à reflexão sobre a mudança de gênero, questionando o porquê de algumas palavras sofrerem modificações e outras não. Em um trecho da aula, aproveitou o "erro" para refletir sobre ele:

Professora - E egoísta?

Aluno 1 - Continua do mesmo jeito.

Aluno 2 - Egoísto!

Professora - Muita gente ficou com dúvida [os alunos se dividiam entre concordar ou não com o colega]... Não é errado, porque a gente só acerta quando a gente erra. Aí vamos ver aqui... essa palavra.

Professora - Vou pegar a ideia de XXXX. Ela disse egoísto, porque, geralmente, quando a gente faz o gênero masculino para o feminino, a gente só faz a troca do "a" pelo "o", não é assim? Geralmente... quer dizer que não são todas as vezes. Aqui no caso: egoísta... o egoísta e a egoísta. Então, a gente chama essa palavra de invariável... o que quer dizer invariável? Ela não é modificada, independente se eu estou me referindo ao sexo feminino ou masculino. Até aí tudo bem? Alguma observação a mais?

Aluno 3 - Ô professora, egoísta serve para masculino e feminino, né? [um aluno fala bem baixinho]

Professora - Isso.

A professora finalizou a discussão sobre a palavra egoísta, explicando o gênero comum-de-dois e dando outros exemplos. Utilizou a nomenclatura e também fez a conceituação a partir do que os alunos perceberam no texto, aproveitando o erro da aluna como objeto de estudo e como mote para a definição. Aqui, o conceito não foi dado a priori, mas partiu do questionamento, da reflexão sobre a língua.

A professora demonstrou perceber esse movimento em sua prática e, parecendo ser consciente de que estava em constante processo de aprendizagem, revelou, nas entrevistas, como o seu fazer na sala de aula é heterogêneo, por vezes até tenso, mas mantém uma unidade com os objetivos que se quer alcançar, como ela mesma testemunhou na epígrafe deste artigo. 


\section{Considerações finais}

Ao analisar os aspectos mais relevantes das práticas de ensino da professora, foi possível ratificar que há um movimento que oscila entre permanências e mudanças no ensino da gramática. Mas, além disso, há, claramente, uma tentativa de promover atividades que ajudem os alunos a desenvolver a competência comunicativa, sem, no entanto, desconsiderar a necessidade de desenvolver um trabalho com análise linguística, articulando-a também aos eixos de leitura e produção de textos.

Os aspectos que apontam para esse movimento apareceram na relação que a professora mantinha com o livro didático adotado pela rede de ensino e o outro que utilizava para ensinar gramática, na maneira como articulou leitura e produção à reflexão sobre a língua, na ênfase do trabalho com leitura e produção de textos e na maneira como abordava os conteúdos gramaticais.

Estamos cientes de que esse é apenas um recorte das práticas dessa professora, mas é possível perceber o quanto é necessário investir em um processo de formação continuada que auxilie os docentes a refletirem sobre suas práticas e minimizarem as angústias decorrentes de um processo de (re)construção no qual se encontram inseridos.

$\mathrm{Na}$ entrevista final, foi dada à professora a oportunidade de fazer um comentário sobre o que ela considerasse importante pontuar. 0 sentimento posto nesse depoimento fala por si só e resume toda essa tentativa de realizar um trabalho que promova a formação de um aluno leitor e escritor, mesmo diante dos entraves externos à sala de aula:

Ah! Sonhar é bom... Eu procuro naquele ano o que for possível para eles... de ajudar, de modificar, de melhorar na aprendizagem e como pessoa.. Eu tenho esse desejo... e da minha parte eu fico desanimada... porque a gente sai, mostra e, às vezes, é tocado em pontos que você já faz... e a coordenação, a direção diz que você não faz, entendeu? Mas o que dá o resultado é o que você vê no aluno... Meu desejo é que eles estejam melhores do que quando começaram... que tenha auxiliado a superar as suas dificuldades... porque escrever não é tão fácil assim... e que... assim... uma marca, uma vontade inspiradora de que eles leiam, que abram os olhos para 0 mundo... e que todo esse trabalho de texto, de gramática, de tudo se transforme num bolo prazeroso... 0 ano que vem eu posso estar com eles ou não, mas que eles tenham superado. Eu ajudei a subir um degrau: esse é o meu desejo.

Considerando as discussões geradas a partir das análises desse trabalho, é possível afirmar, assim, que o ensino de gramática/análise linguística ainda precisa 
ser muito pesquisado e discutido. A reflexão sobre os aspectos linguísticos ainda causa muitos conflitos e insegurança entre os professores, que, além de enfrentar tensões internas provenientes de lacunas na formação inicial, ainda se deparam com uma ausência de formação continuada ou de espaços institucionalizados que promovam a reflexão sobre suas práticas e seus cotidianos e possibilitem um encontro produtivo entre os discursos acadêmicos e os diversos modos de fazer dos professores.

\section{Referências}

NTUNES, Irandé. Aula de português: encontro e interação. São Paulo: Parábola editorial, 2003.

ANTUNES, Irandé. Muito além da gramática: por um ensino de línguas sem pedras no caminho. São Paulo: Parábola editorial, 2007.

BARDIN, Laurence. Análise do conteúdo. Lisboa: Edições 70, 1977.

BRASIL. Guia de livros didáticos; PNLD 2011: Língua Portuguesa -. Brasília: Ministério da Educação, Secretaria de Educação Básica, 2010.

BUSNARDO, Flávia; LOPES, Alice Casimiro. Os discursos da comunidade disciplinar de ensino de biologia: circulação em múltiplos contextos. Ciência \& Educação, Bauru, v. 16, n. 1, pp. 87-102, 2010.

CEREJA, William Roberto, MAGALHÃES, Tereza Cochar. Português: Linguagens, 6.ำ ano. 5. ed. reformulada. São Paulo: Atual, 2009, p. 115

CERTEAU, Michel de. A invenção do cotidiano: 1. Artes de fazer. Tradução Ephraim Ferreira Alves. Petrópolis, RJ: Vozes, 1994.

CHARTIER, Anne-Marie. Fazeres ordinários da classe: uma aposta para pesquisa e para a formação, Educação e Pesquisa. São Paulo, v. 26, n. 2, pp. 157-168, jul./dez. 2000.

CHARTIER, Anne-Marie. Ensinar a ler e escrever, entre teoria e prática. $V$ Semana da Educação, da Fundação Victor Civita. São Paulo: 2010. 20p. Disponível em: <http:// revistaescola.abril.com.br/pdf/texto-anne-marie-chartier.pdf>. Acesso em: 10 dez. 2012. GERALDI, João Wanderley (org.). O texto na sala de aula. 3. ed. São Paulo: Ática, 2003. MARINHO, Marildes. A Língua Portuguesa nos currículos de final de século. In: BARRETO, Elba de Sá et al. Os currículos do ensino fundamental para as escolas brasileiras. Campinas: Autores Associados; São Paulo: Fundação Carlos Chagas, 1998, pp. 43-90.

LÜDKE, Menga. A pesquisa em educação ao encontro de sua complexidade. In: SILVA, Aida Maria M. et al. (Org.). Educação formal e não formal, processos formativos e saberes pedagógicos: desafios para a inclusão social. In: ENCONTRO NACIONAL DE DIDÁTICA E PRÁTICA DE ENSINO, 13., Recife, 2006. Anais... Recife, 2006.

LÜDKE, Menga; ANDRÈ, Marli Elisa Dalmazo Afonso de. Pesquisa em educação: abordagens 
qualitativas. São Paulo: EPU, 1986.

MATTOS E SILVA, Rosa Virgínia. Contradições no ensino do português: a língua que se fala $X$ a língua que se ensina. 7. ed. São Paulo: Contexto, 2011.

MENDONÇA, Márcia. Análise linguística no ensino médio: um novo olhar, um outro objeto. In: BUNZEN; Clécio; MENDONÇA, Márcia (orgs.). Português no ensino médio e formação do professor. São Paulo: Parábola, 2006, pp.199-226.

MENDONÇA, Márcia. Análise linguística: por que e como avaliar. In: MARCURSCHI, Beth; SUASSUNA, Lívia (orgs.). Avaliação em língua portuguesa: contribuições para a prática pedagógica. Belo Horizonte: Autêntica, 2007. pp. 95-109.

MORAIS, Artur Gomes. Mostro à solta ou... "Análise Linguística" na escola: apropriações de professoras das séries iniciais ante as novas prescrições para o ensino de "Gramática". In: Reunião Anual da ANPEd, 25, Caxambu, 2002, Anais.... Caxambu, ANPEd, pp. 1-16. 2002.

MORAIS, Artur. Gomes; SILVA, Alexsandro da. Produção de textos escritos e análise linguística na escola. In: LEAL, Telma Ferraz; BRANDÃO, Ana Carolina Perrusi. (orgs.). Produção de textos na escola: reflexões e práticas no Ensino Fundamental. Belo Horizonte: Autêntica, 2007.

NEVES, Maria Helena de M. Que gramática ensinar na escola? Norma e uso na Língua Portuguesa. São Paulo: Contexto, 2003.

ROSA, Maria Virgínia de Figueirdedo do Couto; ARNOLDI, Marlene Aparecida Gonzales Colombo . A entrevista na pesquisa qualitativa: mecanismo para validação dos resultados. Belo Horizonte: Autêntica, 2008.

SETT, Maria das Graças et al. Para ler o mundo. Língua portuguesa - 6.ํ ano. São Paulo: Scipione, 2009.

SOARES, Magda. Concepções de linguagem e o ensino da Língua Portuguesa. In: BASTOS, Neusa Barbosa (org.). Língua Portuguesa: história, perspectivas, ensino. São Paulo: Educ., 1998, pp. 53-60.

SILVA, Vanessa Souza da; CYRANKA, Lúcia Furtado de Mendonça. A Língua Portuguesa na escola ontem e hoje. Linhas Críticas, Brasília, v. 14, n. 27, pp. 271-287, jul/dez, 2009.

TARDIF, Maurice. Saberes profissionais dos professores e conhecimentos universitários ? Elementos para uma epistemologia da prática profissional dos professores e suas consequências em relação à formação do magistério. Revista Brasileira de Educação, Rio de Janeiro, ANPEd, n. 13, pp. 5-24, jan/fev/mar/abr. 2000.

TARDIF, Maurice; RAYMOND, Danielle. Saberes, tempo e aprendizagem do trabalho no magistério. Educação \& Sociedade, Campinas, vol. 21, n. 73, pp. 209-244, dez. 2000. 
Recebido em dezembro de 2014

Aprovado em abril de 2015

Fabiana Júlia de Araújo Tenório é mestra em Educação pela Universidade Federal de Pernambuco (UFPE), Centro Acadêmico do Agreste e professora do Instituto Federal de Educação, Ciência e Tecnologia de Pernambuco - Pesqueira. E-mail: fabiana_pesqueiradyahoo.com.br

Alexsandro da Silva é doutor em Educação pela Universidade Federal de Pernambuco (UFPE), professor da Universidade Federal de Pernambuco (UFPE) - Campus Agreste e atua no Programa de Pós-Graduação em Educação Contemporânea. E-mail: alexs-silvaQuol.com.br 